\title{
The Research of Nanoparticle and Microparticle Hydroxyapatite Amendment in Multiple Heavy Metals Contaminated Soil Remediation
}

\author{
Zhangwei Li, Man-man Zhou, and Weidian Lin \\ Department of Chemistry, Hanshan Normal University, Chaozhou 521041, China \\ Correspondence should be addressed to Zhangwei Li; 99094001@163.com
}

Received 30 December 2013; Accepted 20 February 2014; Published 20 March 2014

Academic Editor: Wing-Kei Ho

Copyright (C) 2014 Zhangwei Li et al. This is an open access article distributed under the Creative Commons Attribution License, which permits unrestricted use, distribution, and reproduction in any medium, provided the original work is properly cited.

\begin{abstract}
It was believed that when hydroxyapatite (HAP) was used to remediate heavy metal-contaminated soils, its effectiveness seemed likely to be affected by its particle size. In this study, a pot trial was conducted to evaluate the efficiency of two particle sizes of HAP: nanometer particle size of HAP (nHAP) and micrometer particle size of HAP (mHAP) induced metal immobilization in soils. Both mHAP and nHAP were assessed for their ability to reduce lead $(\mathrm{Pb})$, zinc $(\mathrm{Zn})$, copper $(\mathrm{Cu})$, and chromium $(\mathrm{Cr})$ bioavailability in an artificially metal-contaminated soil. The pakchoi (Brassica chinensis L.) uptake and soil sequential extraction method were used to determine the immobilization and bioavailability of $\mathrm{Pb}, \mathrm{Zn}, \mathrm{Cu}$, and $\mathrm{Cr}$. The results indicated that both mHAP and nHAP had significant effect on reducing the uptake of $\mathrm{Pb}, \mathrm{Zn}, \mathrm{Cu}$, and $\mathrm{Cr}$ by pakchoi. Furthermore, both mHAP and nHAP were efficient in covering $\mathrm{Pb}, \mathrm{Zn}, \mathrm{Cu}$, and $\mathrm{Cr}$ from nonresidual into residual forms. However, mHAP was superior to nHAP in immobilization of $\mathrm{Pb}, \mathrm{Zn}, \mathrm{Cu}$, and $\mathrm{Cr}$ in metal-contaminated soil and reducing the $\mathrm{Pb}, \mathrm{Zn}, \mathrm{Cu}$, and $\mathrm{Cr}$ utilized by pakchoi. The results suggested that mHAP had the better effect on remediation multiple metal-contaminated soils than nHAP and was more suitable for applying in in situ remediation technology.
\end{abstract}

\section{Introduction}

Heavy metal pollution in the soil has become a serious environmental problem in China, particularly following the rapid industrialization of the nation. Heavy metal in soil readily accumulates in plants and is then transported through the food chain, thus becoming a major threat to human health [1]. A number of remediation methods have been developed in an attempt to control heavy metal pollution, including the use of organic manure, soil amendment addition, cultivation of heavy metal hyperaccumulator plants, and the application of agroecological engineering techniques $[2,3]$.

Supplementation of phosphate-based materials has been found to have a great effect on immobilizing $\mathrm{Pb}$ in contaminated soil and has recently become a commonly used technique due to its cost-effectiveness and decreased disruptive nature $[4,5]$. Hydroxyapatite (HAP) is considered to be the most effective supplement among P-based materials and is commonly used in $\mathrm{Pb}$-contaminated soil. It has been reported that HAP not only facilitates the remediation of $\mathrm{Pb}$, but it is also quite effective in immobilizing other heavy metals, such as $\mathrm{Zn}, \mathrm{Cd}$, and $\mathrm{Cu}[6,7]$. However, the overall effectiveness of using phosphate to immobilize metals and its mechanisms of action remain unknown.

With the rapid development of nanotechnology there has been an increased usage of HAP nanoparticles put into use in wastewater and for soil remediation. Nanometer size particle HAP (nHAP) has a larger specific surface area than micrometer sized particle HAP (mHAP). Moreover, theoretically nHAP has larger reactivity and sorption capacities than that of common size of HAP $[8,9]$. However, few studies have focused on the remediation differences between mHAP and nHAP. Furthermore, little work has been done identifying the effectiveness of the effect of nHAP on a number of different heavy metals. Therefore, the aim of this study was to compare the effectiveness/differences between mHAP and nHAP to 
reduce the uptake of multiple heavy metals $(\mathrm{Pb}$ and $\mathrm{Zn}, \mathrm{Cu}$ and $\mathrm{Cr}$ ) by plants and to immobilize these heavy metals in contaminated soil.

\section{Material and Methods}

2.1. Soil Sample Properties. The soil samples were derived from vegetable gardens. After being air-dried, the soil samples were grounded to pass through a $10 \mathrm{~mm}$ sieve for the pot trial. Soil $\mathrm{pH}$ was measured in $1: 2.5$ soil water suspensions with a combination $\mathrm{pH}$ electrode. Soil organic matter was determined by wet digestion with $\mathrm{K}_{2} \mathrm{Cr}_{2} \mathrm{O}_{7}$ and $\mathrm{H}_{2} \mathrm{SO}_{4}$; available $\mathrm{N}, \mathrm{P}$, and $\mathrm{K}$ were determined according to standard methods recommended by Lu [10]. Some basic physiochemical properties of the soil and the concentrations of $\mathrm{Pb}, \mathrm{Zn}$, $\mathrm{Cu}$, and $\mathrm{Cr}$ in this soil were listed in Table 1.

2.2. Pot Experiments. Two soil amendments were used in this study: mHAP (micrometer hydroxyapatite, bought from Nanjing Emperor Nano Material Co., ltd., China, average particle diameter $=12 \mu \mathrm{m}$ ) and nHAP (nanometer particle hydroxyapatite, bought from Nanjing Emperor Nano Material Co., ltd., China, average particle diameter $=60 \mathrm{~nm}$ ). No $\mathrm{Pb}, \mathrm{Zn}, \mathrm{Cu}$, and $\mathrm{Cr}$ were detected in these two materials. Both soil amendments were applied at two levels, $15 \mathrm{~g} \cdot \mathrm{kg}^{-1}$ and $30 \mathrm{~g} \cdot \mathrm{kg}^{-1}$. The $\mathrm{Pb}, \mathrm{Zn}, \mathrm{Cu}$, and $\mathrm{Cr}$ were supplied to soil as solutions of $\mathrm{PbSO}_{4}, \mathrm{CuSO}_{4} \cdot 5 \mathrm{H}_{2} \mathrm{O}, \mathrm{ZnSO}_{4} \cdot 7 \mathrm{H}_{2} \mathrm{O}$, and $\mathrm{KCrO}_{4}$. The four soil treatments were T0 (without metals added), T1 (250/100 mg. kg ${ }^{-1} \mathrm{~Pb} / \mathrm{Zn}$ added, resp.), T2 (500/200 mg. $\mathrm{kg}^{-1}$ $\mathrm{Pb} / \mathrm{Zn}$ added, resp.), T3 (100/25 $\mathrm{mg} \cdot \mathrm{kg}^{-1} \mathrm{Cu} / \mathrm{Cr}$ added, resp.), and T4 (200/50 mg. kg ${ }^{-1} \mathrm{Cu} / \mathrm{Cr}$ added, resp.). Altogether, each metal level has mHAP and nHAP treatments. There were four replications in each treatment. The concentration of $\mathrm{Pb}, \mathrm{Zn}$, and $\mathrm{Cu}$ supplied to the soil exceeded those of the soil environmental quality standards in China, so the metal amended soil can be regarded as slightly metal contaminated (T1 and T3 treatment level) and heavy metal contaminated (T2 and T4 treatment level), respectively. Soil amendments were thoroughly mixed with soil prior to potting nitrogen ( $6 \mathrm{~g} \cdot \mathrm{pot}^{-1}$ soil as $\mathrm{NH}_{4} \mathrm{NO}_{3}$ ) and potassium (6 g.pot ${ }^{-1}$ soil as $\mathrm{KCl}$ ). Pots containing $3.0 \mathrm{~kg}$ of soil were used in this experiment. Deionized water was supplied to keep the soil water content to about $60 \%$ of maximum water holding capacity.

The soil was left to equilibrate for 20 days before planting pakchoi (Brassica chinensis L.). Ten pregerminated seeds were sown in each pot. At seven days after emergence, seedlings were thinned to six per pot. The pakchoi was grown in a greenhouse with temperatures between 25 and $30^{\circ} \mathrm{C}$. Pakchois were harvested 60 days after emergence.

2.3. Metal Analysis. After harvest, the pakchois were removed from the pots and cut into two parts: shoots and roots. The shoots and roots were washed three times by deionized water, then put into the oven to dry at $70^{\circ} \mathrm{C}$, and passed through $2 \mathrm{~mm}$ sieve for further experiment. The soil samples were taken from the pots after harvesting the vegetables and were air-dried at room temperature, followed by passing through $0.149 \mathrm{~mm}$ sieve.

$\mathrm{Pb}, \mathrm{Zn}, \mathrm{Cu}$, and $\mathrm{Cr}$ in pakchoi were extracted by using acid digestion mixture $\left(\mathrm{HNO}_{3}\right.$ and $\left.\mathrm{HClO}_{4}\right)$. The pakchoi samples were heated with $\mathrm{HNO}_{3}$ and $\mathrm{HClO}_{4}$ mixture until the color became clear, filtered, reconstituted to the desired volume, and measured by the inductively coupled plasma optical emission spectrometry (ICP-OES) for $\mathrm{Pb}, \mathrm{Zn}, \mathrm{Cu}$, and $\mathrm{Cr}$ content. For the analysis of $\mathrm{Pb}, \mathrm{Zn}, \mathrm{Cu}$, and $\mathrm{Cr}$ in soil, $0.3 \mathrm{~g}$ of homogenized soil samples was digested with $\mathrm{HNO}_{3}, \mathrm{HClO}_{4}$, and $\mathrm{HF}$. The samples were heated until the color became clear, dissolved with several drops of $1 \% \mathrm{HNO}_{3}$, filtered, diluted to a volume of $50 \mathrm{~mL}$ with distilled water, and analyzed for the content of $\mathrm{Pb}, \mathrm{Zn}, \mathrm{Cu}$, and $\mathrm{Cr}[6]$.

2.4. Sequential Extraction of Soil Samples. The method of sequential extraction developed by BCR sequential extraction procedure [11] was employed in this study. Each of the chemical fractions was operationally defined as follows: acid soluble fraction: $1 \mathrm{~g}$ soil (dry wt) was extracted with $40 \mathrm{~mL} 0.1 \mathrm{~mol} \cdot \mathrm{L}^{-1} \mathrm{HOAc}$, shaking for $16 \mathrm{~h}$; reducible fraction: residue from the acid soluble fraction was extracted with $40 \mathrm{~mL} 0.5 \mathrm{~mol} \cdot \mathrm{L}^{-1} \mathrm{NH}_{2} \mathrm{OH}-\mathrm{HCl}$ ( $\mathrm{pH} 1.5$ ) shaking for $16 \mathrm{~h}$; oxidizable fraction: residue from the reducible fraction was extracted with $10 \mathrm{~mL} \mathrm{H}_{2} \mathrm{O}_{2}$ for $1 \mathrm{~h}$ at $85^{\circ} \mathrm{C}$ and an additional $10 \mathrm{~mL} \mathrm{H}_{2} \mathrm{O}_{2}$ for $1 \mathrm{~h}$ at $85^{\circ} \mathrm{C}$, and then $50 \mathrm{~mL} 1 \mathrm{~mol} \cdot \mathrm{L}^{-1} \mathrm{NH}_{4} \mathrm{Ac}$ was added, shaking for $16 \mathrm{~h}$; residual fraction: residue from the oxidizable fraction was digested with $\mathrm{HNO}_{3}-\mathrm{HClO}_{4}-$ HF. After each extraction, separation was performed by centrifugation at 10,000 rpm for $20 \mathrm{~min}$. Metal concentration in the soil solutions was determined by ICP-OES.

2.5. Statistical Analysis. The means and standard deviations (SD) were calculated by Excel 2003. Statistical analysis including the analysis of variance was conducted using SPSS version 17.0 software (SPSS Inc., USA) and differences $(P<0.05)$ between means were determined using the Duncan test. The figures were plotted by origin 7.5 .

\section{Results and Discussions}

3.1. Effect of mHAP and $n H A P$ on the Biomass of the Pakchoi. The biomass of the pakchoi shoots and roots was significantly decreased by metal application at $\mathrm{T} 2$ and $\mathrm{T} 4$ treatment levels but increased at T1 and T3 treatment levels compared to the control treatment (Table 2). This result corresponds with Chen and Cui [12], who reported that, at low metal contaminated treatment level, the growth of plant can be promoted while, at high metal contaminated treatment level, the growth of plant can be stunted down. Excessive heavy metals, such as $\mathrm{Pb}, \mathrm{Zn}, \mathrm{Cu}$, and $\mathrm{Cr}$ contents in soil, have been reported to inhibit the development of root system of plant, block down the photosynthesis, and led to the decrease of plant yield [13]. The application of mHAP and nHAP both increased the shoots and roots biomass of the pakchoi at all the treatment levels. The result showed that, by supplement of $30 \mathrm{~g} \cdot \mathrm{kg}^{-1}$ mHAP, the increment of shoots biomass was $21.98 \%$ in $\mathrm{T} 2$ treatment level and $25.62 \%$ in $\mathrm{T} 4$ treatment 
TABLE 1: Basic properties of the soil.

\begin{tabular}{lcccccccc}
\hline \multirow{2}{*}{$\mathrm{pH}$} & \multirow{2}{*}{ Organic matter $\left(\mathrm{g} \cdot \mathrm{kg}^{-1}\right)$} & $\mathrm{N}$ & $\mathrm{Available}\left(\mathrm{mg} \cdot \mathrm{kg}^{-1}\right)$ & \multicolumn{3}{c}{ Total $\left(\mathrm{mg} \cdot \mathrm{kg}^{-1}\right)$} \\
& & $\mathrm{P}$ & $\mathrm{K}$ & $\mathrm{Pb}$ & $\mathrm{Zn}$ & $\mathrm{Cu}$ & $\mathrm{Cr}$ \\
\hline 4.95 & 14.5 & 88.9 & 11.2 & 95.0 & 42.0 & 60.7 & 23.8 & 55.2 \\
\hline
\end{tabular}

TABLE 2: Biomass of pakchoi (Brassica chinensis L.) grown in the uncontaminated soil and contaminated soil with mHAP and nHAP (dry weigh).

\begin{tabular}{|c|c|c|}
\hline Treatment & Shoot $\left(g \cdot\right.$ pot $^{-1}$ DW $)$ & Root (g.pot $\left.{ }^{-1} \mathrm{DW}\right)$ \\
\hline T0 (CK) & $3.61 \pm 0.26^{\mathrm{efg}}$ & $0.62 \pm 0.04^{\mathrm{bc}}$ \\
\hline $\mathrm{T} 0+1.5 \%$ mHAP & $3.96 \pm 0.28^{\mathrm{ij}}$ & $0.63 \pm 0.08^{\mathrm{cd}}$ \\
\hline $\mathrm{T} 0+3 \%$ mHAP & $3.64 \pm 0.17^{\mathrm{fgh}}$ & $0.62 \pm 0.18^{\mathrm{cd}}$ \\
\hline $\mathrm{T} 0+1.5 \%$ nHAP & $3.83 \pm 0.22^{\mathrm{hi}}$ & $0.64 \pm 0.09^{\text {cde }}$ \\
\hline $\mathrm{T} 0+3 \%$ nHAP & $3.60 \pm 0.31^{\mathrm{efg}}$ & $0.62 \pm 0.11^{b c}$ \\
\hline $\mathrm{T} 1\left(250 / 100 \mathrm{mg} \cdot \mathrm{kg}^{-1} \mathrm{~Pb} / \mathrm{Zn}\right)$ & $3.96 \pm 0.25^{\mathrm{ij}}$ & $0.62 \pm 0.06^{\mathrm{bc}}$ \\
\hline $\mathrm{T} 1+1.5 \%$ mHAP & $4.20 \pm 0.10^{\mathrm{kl}}$ & $0.69 \pm 0.18^{\text {efgh }}$ \\
\hline $\mathrm{T} 1+3 \% \mathrm{mHAP}$ & $4.31 \pm 0.53^{1}$ & $0.82 \pm 0.09^{\mathrm{k}}$ \\
\hline $\mathrm{T} 1+1.5 \%$ nHAP & $4.04 \pm 0.16^{\mathrm{ij}}$ & $0.65 \pm 0.13^{\text {cdef }}$ \\
\hline $\mathrm{T} 1+3 \% \mathrm{nHAP}$ & $4.15 \pm 0.14^{\mathrm{jkl}}$ & $0.66 \pm 0.10^{\text {cdef }}$ \\
\hline $\mathrm{T} 2\left(500 / 200 \mathrm{mg} \cdot \mathrm{kg}^{-1} \mathrm{~Pb} / \mathrm{Zn}\right)$ & $3.23 \pm 0.12^{\mathrm{bc}}$ & $0.56 \pm 0.11^{\mathrm{ab}}$ \\
\hline $\mathrm{T} 2+1.5 \%$ mHAP & $3.39 \pm 0.18^{\text {cde }}$ & $0.65 \pm 0.07^{\text {cdef }}$ \\
\hline $\mathrm{T} 2+3 \%$ mHAP & $3.94 \pm 0.27^{\mathrm{ij}}$ & $0.76 \pm 0.21^{\mathrm{ij}}$ \\
\hline $\mathrm{T} 2+1.5 \%$ nHAP & $3.40 \pm 0.43^{\text {cde }}$ & $0.61 \pm 0.11^{b c}$ \\
\hline $\mathrm{T} 2+3 \%$ nHAP & $3.59 \pm 0.15^{\mathrm{efg}}$ & $0.69 \pm 0.15^{\mathrm{dgh}}$ \\
\hline T3 $\left(100 / 25 \mathrm{mg} \cdot \mathrm{kg}^{-1} \mathrm{Cu} / \mathrm{Cr}\right)$ & $3.81 \pm 0.34^{\mathrm{hi}}$ & $0.66 \pm 0.17^{\text {cdef }}$ \\
\hline $\mathrm{T} 3+1.5 \%$ mHAP & $4.01 \pm 0.18^{\mathrm{ijk}}$ & $0.80 \pm 0.09^{\mathrm{jk}}$ \\
\hline $\mathrm{T} 3$ + 3\% mHAP & $4.06 \pm 0.16^{\mathrm{jk}}$ & $0.82 \pm 0.11^{\mathrm{k}}$ \\
\hline $\mathrm{T} 3+1.5 \%$ nHAP & $3.97 \pm 0.49^{\mathrm{ijk}}$ & $0.74 \pm 0.15^{\mathrm{hij}}$ \\
\hline $\mathrm{T} 3+3 \%$ nHAP & $4.04 \pm 0.59^{\mathrm{ijk}}$ & $0.78 \pm 0.08^{\mathrm{ijk}}$ \\
\hline $\mathrm{T} 4\left(200 / 50 \mathrm{mg} \cdot \mathrm{kg}^{-1} \mathrm{Cu} / \mathrm{Cr}\right)$ & $2.81 \pm 0.10^{\mathrm{a}}$ & $0.51 \pm 0.12^{\mathrm{a}}$ \\
\hline $\mathrm{T} 4+1.5 \%$ mHAP & $3.27 \pm 0.25^{\mathrm{bc}}$ & $0.64 \pm 0.11^{\text {cdef }}$ \\
\hline $\mathrm{T} 4+3 \%$ mHAP & $3.53 \pm 0.24^{\mathrm{ef}}$ & $0.71 \pm 0.18^{\mathrm{gh}}$ \\
\hline $\mathrm{T} 4+1.5 \%$ nHAP & $3.08 \pm 0.11^{b}$ & $0.64 \pm 0.06^{\text {cdef }}$ \\
\hline $\mathrm{T} 4+3 \%$ nHAP & $3.31 \pm 0.19^{\mathrm{cd}}$ & $0.67 \pm 0.13^{\text {cdef }}$ \\
\hline
\end{tabular}

Mean values denoted by the same letter in a column do not differ significantly according to the Duncan test.

level as compared to control. As to the nHAP, it was showed that when treated with $30 \mathrm{~g} \cdot \mathrm{kg}^{-1}$ nHAP, the increment of shoots biomass was $11.14 \%$ in T2 treatment level and $17.79 \%$ in T4 treatment level when compared to that of control. It can be found that the application of mHAP and nHAP both increased the shoots and roots biomass of the pakchoi in all treatment levels. This result may be due to the fact that the mHAP and nHAP can release the toxic effect on pakchoi caused by heavy metal treatment, resulting in the increment of the biomass of pakchoi. Another reason may lie in the fact that more phosphate nutrition supplement after phosphate amendments addition can promote the growth of the pakchoi [6]. Furthermore, in this study, mHAP appeared to be more efficient in increasing the biomass of pakchoi in T2 and T4 treatment levels.

3.2. Effect of mHAP and $n H A P$ on the Uptake of $\mathrm{Pb}, \mathrm{Zn}, \mathrm{Cu}$, and $\mathrm{Cr}$ by Pakchoi. The application of mHAP and nHAP significantly reduced the concentration of $\mathrm{Pb}, \mathrm{Zn}, \mathrm{Cu}$, and $\mathrm{Cr}$ in the shoots and roots of the pakchoi grown in the contaminated soil (Tables 3 and 4). However, the addition of mHAP has better effect than nHAP in heavy metal treatment levels (T2 and T4). The result showed that, by the addition of the $30 \mathrm{~g} \cdot \mathrm{kg}^{-1}$ mHAP, the concentrations of $\mathrm{Pb}, \mathrm{Zn}, \mathrm{Cu}$, and $\mathrm{Cr}$ in shoots decreased by $58.1 \%, 47.3 \%, 49.4 \%$, and $38.9 \%$ in T2 and T4 treatment level, respectively, while the roots reduction was $53.0 \%, 45.5 \%, 47.5 \%$, and $44.6 \%$ compared to the control. As to the $30 \mathrm{~g} \cdot \mathrm{kg}^{-1} \mathrm{nHAP}$ application, the reduction in concentration of $\mathrm{Pb}, \mathrm{Zn}, \mathrm{Cu}$, and $\mathrm{Cr}$ in the shoots was $53.4 \%$ for $\mathrm{Pb}, 32.1 \%$ for $\mathrm{Zn}, 32.2 \%$ for $\mathrm{Cu}$, and $30.9 \%$ for $\mathrm{Cr}$ in $\mathrm{T} 2$ and $\mathrm{T} 4$ treatment levels, respectively, whereas roots $\mathrm{Pb}, \mathrm{Zn}, \mathrm{Cu}$, and $\mathrm{Cr}$ decreased by $42.2 \%$ for $\mathrm{Pb}$, $39.3 \%$ for $\mathrm{Zn}, 39.6 \%$ for $\mathrm{Cu}$, and $37.5 \%$ for $\mathrm{Cr}$ when compared with that of control. The result showed that both the mHAP and nHAP can significantly influence $\mathrm{Pb}, \mathrm{Zn}, \mathrm{Cu}$, and $\mathrm{Cr}$ concentrations in the pakchoi vegetable shoots and roots. 
TABLE 3: Concentration of $\mathrm{Pb}$ and $\mathrm{Zn}$ in pakchoi (Brassica chinensis L.) grown in $\mathrm{Pb}-\mathrm{Zn}$ multiple metal-contaminated soil in pot culture receiving mHAP and nHAP amendments (dry weigh).

\begin{tabular}{|c|c|c|c|c|}
\hline & \multicolumn{2}{|c|}{$\mathrm{Pb}$} & \multicolumn{2}{|c|}{$\mathrm{Zn}$} \\
\hline & Shoot $\left(\mathrm{mg} \cdot \mathrm{kg}^{-1}\right)$ & $\operatorname{Root}\left(\mathrm{mg} \cdot \mathrm{kg}^{-1}\right)$ & Shoot $\left(\mathrm{mg} \cdot \mathrm{kg}^{-1}\right)$ & $\operatorname{Root}\left(\mathrm{mg} \cdot \mathrm{kg}^{-1}\right)$ \\
\hline T0 (CK) & $0.40 \pm 0.02^{\mathrm{a}}$ & $2.93 \pm 0.15^{\mathrm{a}}$ & $28.05 \pm 1.66^{\mathrm{bcd}}$ & $38.29 \pm 1.94^{\mathrm{f}}$ \\
\hline $\mathrm{T} 0+1.5 \%$ mHAP & $0.34 \pm 0.02^{\mathrm{a}}$ & $2.62 \pm 0.12^{\mathrm{a}}$ & $24.54 \pm 0.99^{\mathrm{b}}$ & $31.88 \pm 1.87^{\mathrm{d}}$ \\
\hline $\mathrm{T} 0+3 \%$ mHAP & $0.32 \pm 0.03^{\mathrm{a}}$ & $2.25 \pm 0.10^{\mathrm{a}}$ & $18.45 \pm 1.24^{\mathrm{a}}$ & $24.90 \pm 1.99^{\mathrm{a}}$ \\
\hline T0+ 1.5\% nHAP & $0.34 \pm 0.01^{\mathrm{a}}$ & $2.43 \pm 0.09^{\mathrm{a}}$ & $24.90 \pm 1.02^{\mathrm{bc}}$ & $31.22 \pm 2.93^{\mathrm{cd}}$ \\
\hline T0 + 3\% nHAP & $0.30 \pm 0.02^{\mathrm{a}}$ & $2.22 \pm 0.07^{\mathrm{a}}$ & $20.35 \pm 1.73^{\mathrm{a}}$ & $27.23 \pm 2.17^{\mathrm{b}}$ \\
\hline $\mathrm{T} 1$ & $4.45 \pm 0.23^{\mathrm{d}}$ & $26.92 \pm 0.76^{\mathrm{de}}$ & $40.91 \pm 2.36^{\mathrm{f}}$ & $48.53 \pm 2.05^{\mathrm{g}}$ \\
\hline $\mathrm{T} 1+1.5 \%$ mHAP & $3.48 \pm 0.11^{\mathrm{c}}$ & $20.20 \pm 1.54^{\mathrm{c}}$ & $30.47 \pm 1.41^{\mathrm{de}}$ & $32.91 \pm 1.07^{\mathrm{d}}$ \\
\hline $\mathrm{T} 1$ + 3\% mHAP & $1.80 \pm 0.08^{\mathrm{b}}$ & $15.08 \pm 0.88^{\mathrm{b}}$ & $22.52 \pm 0.23^{\mathrm{a}}$ & $29.31 \pm 2.44^{b c}$ \\
\hline $\mathrm{T} 1+1.5 \%$ nHAP & $3.42 \pm 0.21^{\mathrm{c}}$ & $22.14 \pm 1.32^{\mathrm{c}}$ & $32.24 \pm 2.00^{\mathrm{e}}$ & $35.53 \pm 2.82^{\mathrm{e}}$ \\
\hline $\mathrm{T} 1+3 \%$ nHAP & $2.16 \pm 0.08^{\mathrm{b}}$ & $16.39 \pm 1.00^{\mathrm{b}}$ & $25.80 \pm 1.25^{\mathrm{bc}}$ & $31.39 \pm 1.63^{\mathrm{cd}}$ \\
\hline $\mathrm{T} 2$ & $12.15 \pm 0.77^{\mathrm{h}}$ & $53.94 \pm 2.69^{h}$ & $51.02 \pm 3.58^{\mathrm{g}}$ & $86.84 \pm 5.85^{\mathrm{k}}$ \\
\hline $\mathrm{T} 2+1.5 \%$ mHAP & $7.21 \pm 0.62^{\mathrm{g}}$ & $28.25 \pm 1.36^{\mathrm{e}}$ & $31.63 \pm 1.97^{\mathrm{e}}$ & $59.50 \pm 2.55^{\mathrm{i}}$ \\
\hline $\mathrm{T} 2+3 \%$ mHAP & $5.09 \pm 0.39^{\mathrm{e}}$ & $25.35 \pm 1.82^{\mathrm{d}}$ & $26.89 \pm 1.55^{\mathrm{bc}}$ & $47.37 \pm 3.43^{\mathrm{g}}$ \\
\hline $\mathrm{T} 2+1.5 \%$ nHAP & $7.59 \pm 0.56^{\mathrm{g}}$ & $37.67 \pm 2.04^{\mathrm{g}}$ & $38.44 \pm 1.61^{\mathrm{f}}$ & $63.83 \pm 5.01^{\mathrm{j}}$ \\
\hline $\mathrm{T} 2+3 \%$ nHAP & $5.66 \pm 0.50^{\mathrm{f}}$ & $31.20 \pm 1.91^{\mathrm{f}}$ & $31.59 \pm 1.26^{\mathrm{e}}$ & $52.70 \pm 3.38^{\mathrm{h}}$ \\
\hline
\end{tabular}

Mean values denoted by the same letter in a column do not differ significantly according to the Duncan test.

TABle 4: Concentration of $\mathrm{Cu}$ and $\mathrm{Cr}$ in pakchoi (Brassica chinensis $\mathrm{L}$.) grown in $\mathrm{Cu}-\mathrm{Cr}$ multiple metal-contaminated soil in pot culture receiving mHAP and nHAP amendments.

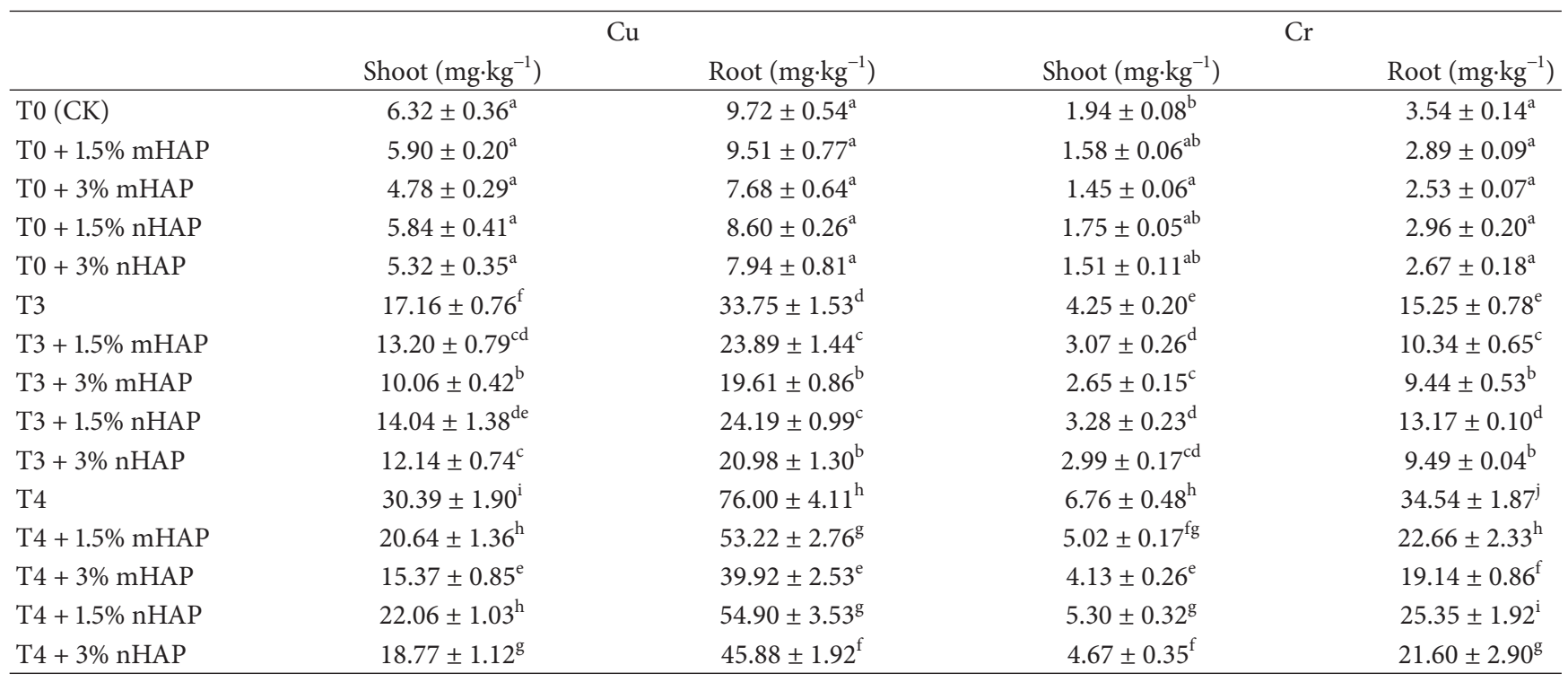

Mean values denoted by the same letter in a column do not differ significantly according to the Duncan test.

Similar to the result of pakchoi biomass, the mHAP has better effect on reducing the $\mathrm{Pb}, \mathrm{Zn}$ content in $\mathrm{T} 2$ treatment and $\mathrm{Cu}, \mathrm{Cr}$ content in $\mathrm{T} 4$ treatment in pakchoi shoots and roots. However, it can be observed that the application of $30 \mathrm{~g} \cdot \mathrm{kg}^{-1}$ mHAP can significantly reduce the $\mathrm{T} 1$ and $\mathrm{T} 3$ concentration level of metals in pakchois and therefore produce vegetable with $\mathrm{Pb}, \mathrm{Zn}, \mathrm{Cu}$, and $\mathrm{Cr}$ concentrations under the Chinese national food safety standard (GB2762-2005, in China) level.

3.3. Effect of mHAP and nHAP on the $p H$ of the Soil. Some researchers [14] suggested that the $\mathrm{pH}$ was one of the most important parameters affected metal bioavailability to plants. In the low $\mathrm{pH}(\mathrm{pH}<5)$ condition, the metal in soil has higher solubility. As a result, more metal ion released to the soil solution. The metal therefore was more bioavailable to the plants. The application of HAP amendment can increase the soil $\mathrm{pH}$ and reduce the metal bioavailability, especially in the low $\mathrm{pH}$ soil conditions. This study indicated that the supplement of mHAP and nHAP both significantly increased the soil $\mathrm{pH}$ compared to the unamended metals contaminated soil (Table 5). However, it can be observed that the mHAP had better effect than nHAP in increasing the $\mathrm{pH}$ of each 
TABLE 5: $\mathrm{pH}$ value in the tested soil as affected by mHAP and nHAP amendments.

\begin{tabular}{ll}
\hline Treatment & $\mathrm{pH}$ \\
\hline $\mathrm{T} 0(\mathrm{CK})$ & 4.95 \\
$\mathrm{~T} 0+1.5 \%$ mHAP & 5.46 \\
$\mathrm{~T} 0+3 \%$ mHAP & 5.99 \\
$\mathrm{~T} 0+1.5 \%$ nHAP & 5.20 \\
$\mathrm{~T} 0+3 \%$ nHAP & 5.76 \\
$\mathrm{~T} 1$ & 5.08 \\
$\mathrm{~T} 1+1.5 \%$ mHAP & 5.76 \\
$\mathrm{~T} 1+3 \%$ mHAP & 6.07 \\
$\mathrm{~T} 1+1.5 \%$ nHAP & 5.42 \\
$\mathrm{~T} 1+3 \%$ nHAP & 5.83 \\
$\mathrm{~T} 3$ & 5.11 \\
$\mathrm{~T} 3+1.5 \%$ mHAP & 5.60 \\
$\mathrm{~T} 3+3 \%$ mHAP & 5.99 \\
$\mathrm{~T} 3+1.5 \%$ nHAP & 5.18 \\
$\mathrm{~T} 3+3 \%$ nHAP & 5.74 \\
$\mathrm{~T} 2$ & 5.16 \\
$\mathrm{~T} 2+1.5 \%$ mHAP & 5.72 \\
$\mathrm{~T} 2+3 \%$ mHAP & 6.24 \\
$\mathrm{~T} 2+1.5 \%$ nHAP & 5.45 \\
$\mathrm{~T} 2+3 \% \mathrm{nHAP}$ & 5.74 \\
$\mathrm{~T} 4$ & 4.97 \\
$\mathrm{~T} 4+1.5 \%$ mHAP & 5.68 \\
$\mathrm{~T} 4+3 \%$ mHAP & 6.19 \\
$\mathrm{~T} 4+1.5 \%$ nHAP & 5.39 \\
$\mathrm{~T} 4+3 \%$ nHAP & 5.87 \\
\hline & \\
&
\end{tabular}

treatment level, especially in $30 \mathrm{~g} \cdot \mathrm{kg}^{-1}$ application rate. The result showed that when compared with the contaminated soil without adding amendment, after applying for $30 \mathrm{~g} \cdot \mathrm{kg}^{-1}$ mHAP, the $\mathrm{pH}$ value was raised by 0.99 in T1 treatment level, 1.08 in T2 treatment level, 0.88 in T3 treatment level, and 1.22 in T4 treatment level. As to the nHAP, the enhancement of $\mathrm{pH}$ value was 0.75 in T1 treatment level, 0.58 in T2 treatment level, 0.63 in T3 treatment level, and 0.90 in T4 treatment level when compared with the contaminated soil without adding amendment.

$\mathrm{pH}$ was an important parameter which affected metal immobilization and dissolution in soil [15]. The metal solubility and mobility increased with the decrease of $\mathrm{pH}$. In contrast, when the soil $\mathrm{pH}$ increased, the solubility and mobility of metal in soil went down. Bolisson et al. [16] reported that the application of HAP can increase the soil $\mathrm{pH}$ value. This was attributed to the fact that the dissolution of HAP in soil solution can consume $\mathrm{H}^{+}$, resulting in the increase of soil $\mathrm{pH}$ :

$$
\mathrm{Ca}_{10}\left(\mathrm{PO}_{4}\right)_{6}(\mathrm{OH})_{2}+14 \mathrm{H}^{+}=10 \mathrm{Ca}^{2+}+6 \mathrm{H}_{2} \mathrm{PO}_{4}{ }^{-}+2 \mathrm{H}_{2} \mathrm{O}
$$

It was reported that when HAP was dissolved in deionized water and $0.1 \mathrm{~mol} / \mathrm{L} \mathrm{KNO}_{3}$ solution, the dissolution rate of HAP mainly depended on $\mathrm{pH}[17,18]$. Soil solution was more complicated when compared with deionized water or single electrolyte solution. Generally speaking, in low $\mathrm{pH}$ soil condition, the dissolution rate of HAP was more faster than in neutral and alkali soil. As in the acidic soil condition, the $\mathrm{PO}_{4}{ }^{3-}$ in hydroxyapatite had higher efficiency to dissolve and release to the soil solution. In this study, the application of mHAP had better effect in increasing the soil $\mathrm{pH}$ than nHAP, suggesting that mHAP has a larger dissolution rate than nHAP.

3.4. Speciation of Soil $\mathrm{Pb}, \mathrm{Zn}, \mathrm{Cu}$, and $\mathrm{Cr}$. The distribution of $\mathrm{Pb}, \mathrm{Zn}, \mathrm{Cu}$, and $\mathrm{Cr}$ in the uncontaminated soil and metal-contaminated soil as analyzed by the BCR sequential extraction method was shown in Figure 1. The metal $(\mathrm{Pb}, \mathrm{Zn}$, $\mathrm{Cu}$, and $\mathrm{Cr}$ ) in the treatments without mHAP and nHAP was mainly associated with the nonresidual fraction. The percentage of $\mathrm{Pb}, \mathrm{Zn}$, and $\mathrm{Cu}$ bound with the nonresidual fraction (including acid soluble fraction, reducible fraction, and oxidizable fraction) accounted for over $74.1 \%$ for $\mathrm{Pb}$ and $76.3 \%$ for $\mathrm{Zn}$ in $\mathrm{T} 1$ treatment level and $79.72 \%$ for $\mathrm{Pb}$ and $62.96 \%$ for $\mathrm{Zn}$ in T2 treatment level, $88.1 \%$ for $\mathrm{Cu}$ and $60.73 \%$ for $\mathrm{Cr}$ in $\mathrm{T} 3$ treatment level, and $88.12 \%$ for $\mathrm{Cu}$ and $56.47 \%$ for $\mathrm{Cr}$ in $\mathrm{T} 4$ treatment level, respectively. This indicated that a substantial fraction of $\mathrm{Pb}, \mathrm{Zn}, \mathrm{Cu}$, and $\mathrm{Cr}$ in the contaminated soil without amendment may be available for pakchoi to uptake. As to the HAP amended soil, both mHAP and nHAP translocated nonresidual fractions of $\mathrm{Pb}, \mathrm{Zn}, \mathrm{Cu}$, and $\mathrm{Cr}$ to the residual fraction. For instance, by addition of $30 \mathrm{~g} \mathrm{~kg}^{-1}$ mHAP, the reduction in the nonresidual fraction was $36.0 \%$ for $\mathrm{Pb}$ and $34.9 \%$ for $\mathrm{Zn}$ in $\mathrm{T} 1$ treatment level, 36.1\% for $\mathrm{Pb}$ and $27.5 \%$ for $\mathrm{Zn}$ in $\mathrm{T} 2$ treatment level, $32.5 \%$ for $\mathrm{Cu}$ and $26.8 \%$ for $\mathrm{Cr}$ in $\mathrm{T} 3$ treatment level, and $26.6 \%$ for $\mathrm{Cu}$ and $20.0 \%$ for $\mathrm{Cr}$ in $\mathrm{T} 4$ treatment level. The reduction in the nonresidual fraction was $29.8 \%$ for $\mathrm{Pb}$ and $29.4 \%$ for $\mathrm{Zn}$ in $\mathrm{T} 1$ treatment level, $20.7 \%$ for $\mathrm{Pb}$ and $27.5 \%$ for $\mathrm{Zn}$ in $\mathrm{T} 2$ treatment level, 23.1\% for $\mathrm{Cu}$ and 21.9\% for Cr in T3 treatment level, and $17.1 \%$ for $\mathrm{Cu}$ and $14.8 \%$ for $\mathrm{Cr}$ in $\mathrm{T} 4$ treatment level by addition of $30 \mathrm{~g} \mathrm{~kg}^{-1} \mathrm{nHAP}$ treatment.

The result showed that nonresidual fraction of $\mathrm{Pb}, \mathrm{Zn}$, $\mathrm{Cu}$, and $\mathrm{Cr}$ decreased with the increase of soil $\mathrm{pH}$, hinting that the $\mathrm{pH}$ values play an important role in decreasing the nonresidual fraction. The increase of $\mathrm{pH}$ values induced by HAP favored the precipitation of heavy metals. In addition, Gray et al. [19] found that the increase of soil $\mathrm{pH}$ values increased the negative charges of variably charged colloids in soil, such as organic matter, clays, $\mathrm{Fe}$ and $\mathrm{Al}$ oxides, and silicon oxides, resulting in stronger sorption and precipitation of heavy metals and hence lower soluble metal concentrations in soil. In this study, it can be found that mHAP has better effect on transforming metals from the nonresidual to the residual fraction, which was consistent with the result of soil $\mathrm{pH}$ changed by mHAP and nHAP, indicating that larger soil $\mathrm{pH}$ values with mHAP addition than nHAP were the main reason for the superior ability of immobilization $\mathrm{Pb}, \mathrm{Zn}, \mathrm{Cu}$, and $\mathrm{Cr}$ in soil of mHAP.

In this paper, we identified the effectiveness of mHAP and nHAP to reduce the amounts of heavy metals in contaminated soil. The efficiency of in situ remediation of metalcontaminated soils can be evaluated by using fractionation 


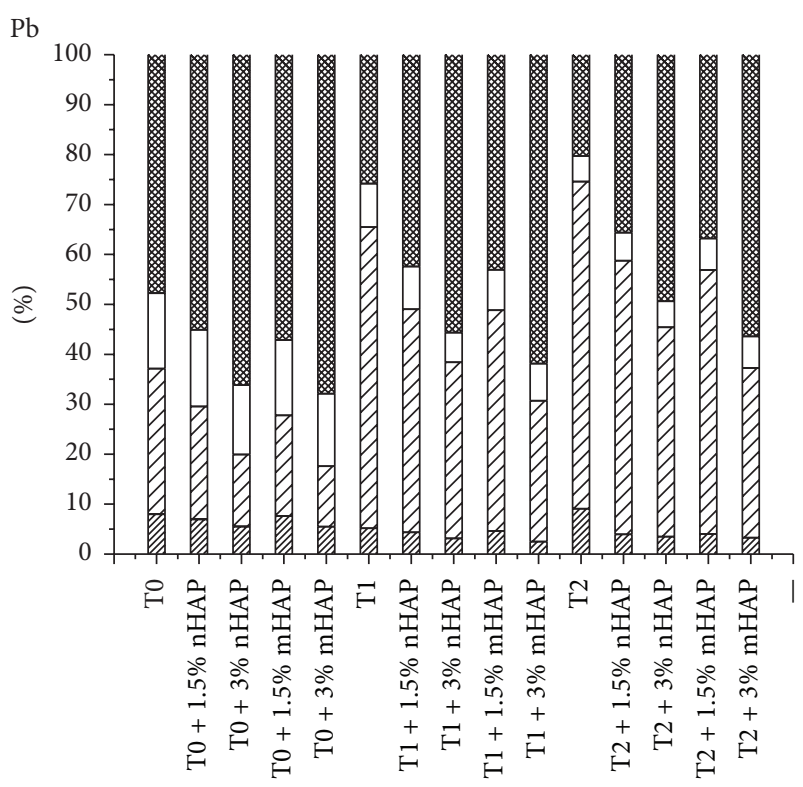

שाI Acid soluble VID Reducible

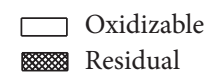

(a)

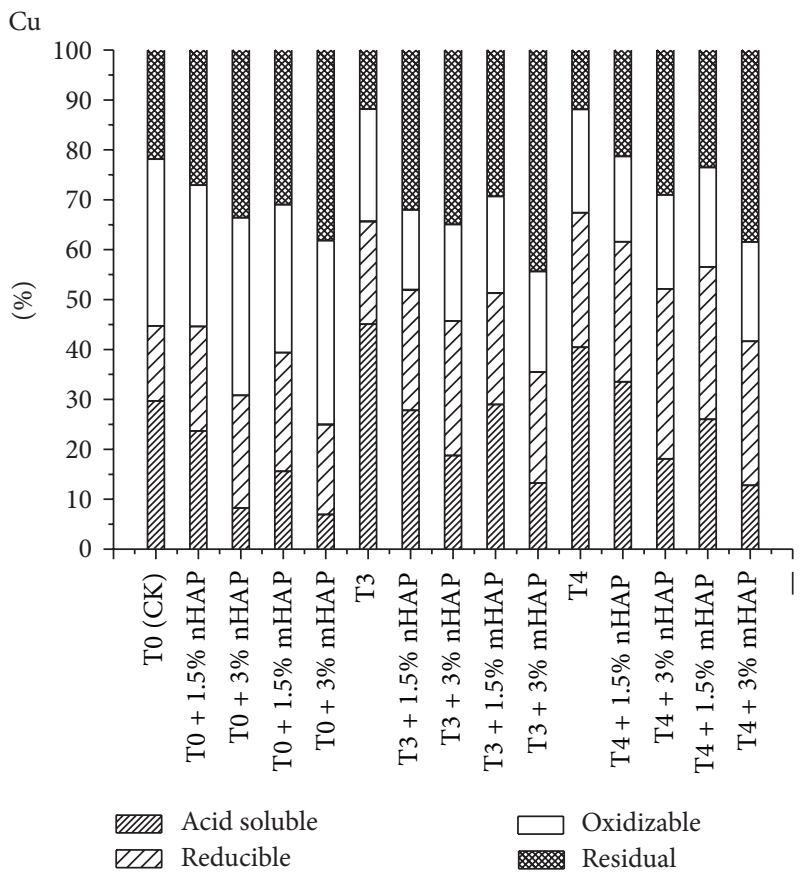

(c)

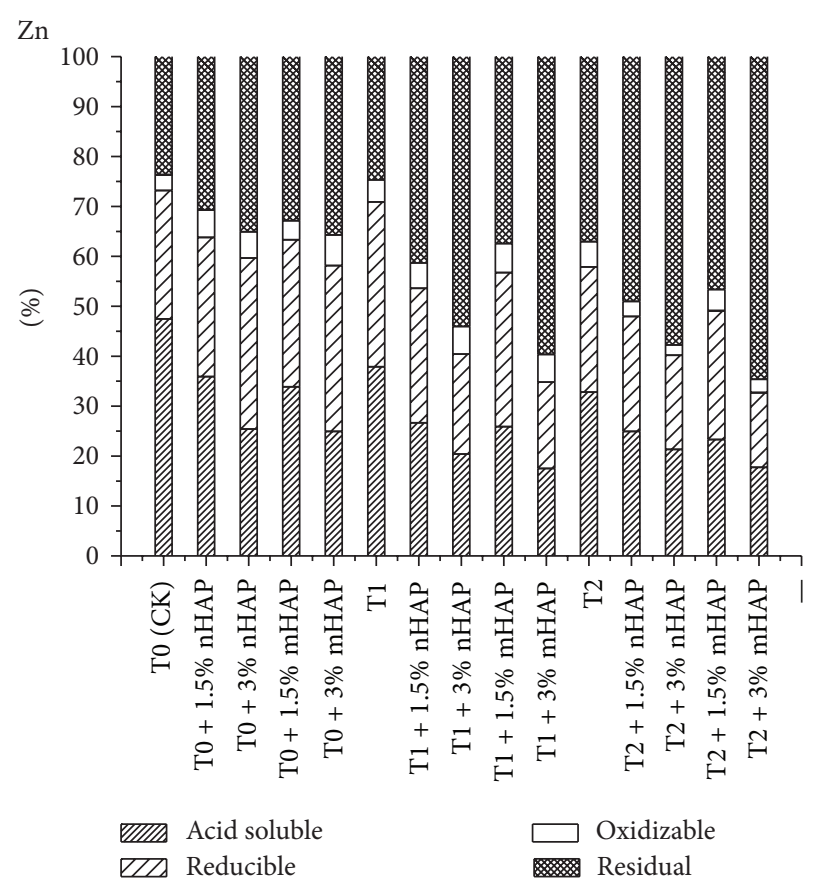

(b)

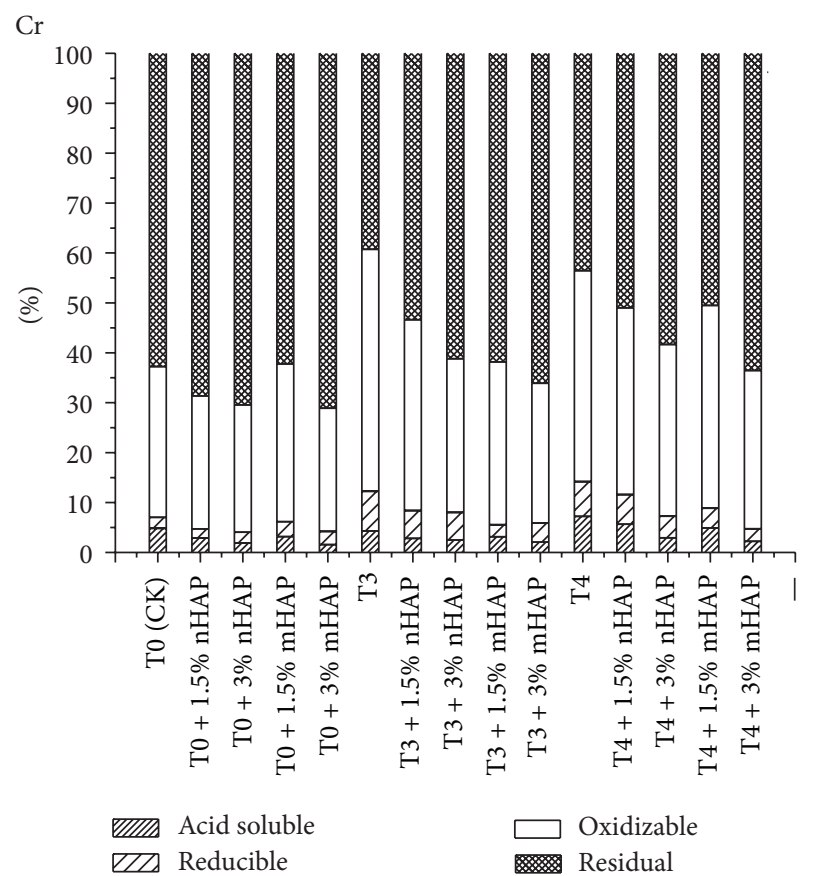

(d)

Figure 1: Relative percentages of $\mathrm{Pb}, \mathrm{Zn}, \mathrm{Cu}$, and $\mathrm{Cr}$ in each fraction of the soils from the $\mathrm{CK}$, mHAP, and nHAP treated pots.

procedures; the more effective the treatment, the greater the amount of metals transferred from the nonresidual to the residual fraction [20,21]. BCR sequential extraction procedures were widely used to assess the bioavailability and mobility of heavy metals in soils as well as the efficacy of decontamination amendment. The nonresidual metal fractionation, which includes acid soluble (weakly bound with organic matter and carbonates fraction), reducible (iron and manganese oxides fraction), and oxidizable (organically bound and sulfide fraction) fractions, is more mobile and is considered to have a higher bioavailability as compared with the residual fraction $[22,23]$. In the current study, both mHAP and nHAP were highly capable of modifying $\mathrm{Pb}$, $\mathrm{Zn}, \mathrm{Cu}$, and $\mathrm{Cr}$ in contaminated soils, with a concurrent 
increase in the residual fractionation and a decrease in the nonresidual fractionation, especially the acid soluble fractionation. Moreover, mHAP and nHAP were more effective in transforming the nonresidual fractionation of $\mathrm{Pb}$ than the other three heavy metals, as expected. One of the most important effects of HAP modification is the formation of pyromorphite from $\mathrm{Pb}$, thus resulting in the transformation of $\mathrm{Pb}$ from nonresidual fractions to the residual fraction [24]. This study confirmed that the supplementation of both mHAP and nHAP significantly enhanced the residual fraction of $\mathrm{Pb}$ in soils, corresponding to a reduction of $\mathrm{Pb}$ in pakchoi shoots and roots.

We also found that the addition of mHAP and nHAP decreased the nonresidual fraction of $\mathrm{Cu}, \mathrm{Zn}$, and $\mathrm{Cr}$ in the soil. However, the immobilization efficacy was lower than $\mathrm{Pb}$. We hypothesized two reasons for this phenomenon. Firstly, the solubility products of $\mathrm{Cu}, \mathrm{Zn}$, and $\mathrm{Cr}$ phosphate are known to be much greater than that of $\mathrm{Pb}$ phosphate. However, hopeite $\left[\mathrm{Zn}_{3}\left(\mathrm{PO}_{4}\right)_{2}\right], \mathrm{Cu}_{3}\left(\mathrm{PO}_{4}\right)_{2}$, and $\mathrm{Cr}_{2}\left(\mathrm{PO}_{4}\right)_{7}$ are much more soluble than pyromorphite. As such, $\mathrm{Cu}, \mathrm{Zn}$, and $\mathrm{Cr}$ phosphate may not control the solubility of these heavy metals in this case [6]. And secondly, we believe that the primary mechanism is likely due to the adsorption potential of the surface of HAP. For instance, Cao et al. [25] reported that the application of $\mathrm{HAP}$ in $\mathrm{Pb}, \mathrm{Cu}$, and $\mathrm{Zn}$ contaminated soil and showed that $78 \%$ of $\mathrm{Pb}$ that reacted with HAP was formed of pyromorphite. Meanwhile, only $25 \%$ of $\mathrm{Cu}$ and $5 \%$ of $\mathrm{Zn}$ were formed of $\mathrm{Cu}_{2}\left(\mathrm{PO}_{4}\right)_{3}$ and $\mathrm{Zn}_{2}\left(\mathrm{PO}_{4}\right)$ and $75 \% \mathrm{Cu}$ and $95 \% \mathrm{Zn}$ were adsorbed upon the surface of HAP. Results from this study confirmed that mHAP and nHAP had great ability for reducing $\mathrm{Pb}$ bioavailability and also for inhibiting the uptake of $\mathrm{Pb}$ to a greater degree than $\mathrm{Zn}, \mathrm{Cu}$, and $\mathrm{Cr}$. However, mHAP was more capable of decreasing the overall amount of metals taken up by the pakchoi plant.

The reduction of $\mathrm{Pb}$ content in the pakchoi shoots and roots can be attributed to the formation of pyromorphite in the soil. As to the decrease of $\mathrm{Zn}, \mathrm{Cu}$, and $\mathrm{Cr}$ in pakchoi shoots and roots, the main reason involved of $\mathrm{Zn}, \mathrm{Cu}$ and $\mathrm{Cr}$ adsorption on the HAP and the higher solubility of $\left[\mathrm{Zn}_{3}\left(\mathrm{PO}_{4}\right)_{2}\right]$, $\mathrm{Cd}_{3}\left(\mathrm{PO}_{4}\right)_{2}$ and $\mathrm{Cr}_{2}\left(\mathrm{PO}_{4}\right)_{7}$ than pyromorphite. Moreover, the reduction of $\mathrm{Pb}, \mathrm{Zn}, \mathrm{Cu}$, and $\mathrm{Cr}$ content in the pakchoi shoots and roots was as follows: $\mathrm{Pb}>\mathrm{Zn} \approx \mathrm{Cu}>\mathrm{Cr}$. These results are consistent with the sequence in the reduction of $\mathrm{Pb}, \mathrm{Zn}, \mathrm{Cu}$, and $\mathrm{Cr}$ of the nonresidual fraction found in contaminated soil, suggesting that the nonresidual fraction of heavy metals can readily be taken up by the pakchoi plant and also shows the highest levels of bioavailability for the pakchoi.

Many studies have been conducted in recent years focused on the heavy metal remediation potential of nanomaterials in contaminated soil [26, 27]. Phosphate-based nanoparticles have been found to be one of the most effective nanomaterials for the reclamation of heavy metal contaminated soil. For instance, Liu and Zhao [28] reported that the application of iron phosphate nanoparticles in $\mathrm{Pb}$ contaminated soil can effectively reduce the leachability and bioavailability of $\mathrm{Pb}^{2+}$ in soil. Moreover, Liu [29] also reported an effective reclamation of a lead-contaminated soil using synthesized apatite nanoparticles. Their experimental results clearly showed that the apatite nanoparticles solution could significantly reduce the TCLP-leachable $\mathrm{Pb}$ fraction in $\mathrm{Pb}$-contaminated soil by $9.56 \%$ to $66.43 \%$. Many studies have suggested that nanomaterials are superior to traditional modifications using commonly particle sizes for soil remediation due to nanomaterials having a higher reactivity and a greater ability for absorption and for its relatively easy delivery methods. Theoretically, in this study a larger amount of $\mathrm{Pb}, \mathrm{Zn}, \mathrm{Cu}$, and $\mathrm{Cr}$ was able to be immobilized by nHAP, likely due to its smaller particle sizes yet larger surface area, as compared to mHAP. However, we found that mHAP was more effective than nHAP in immobilizing $\mathrm{Pb}, \mathrm{Zn}, \mathrm{Cu}$, and $\mathrm{Cr}$. Furthermore, the $\mathrm{pH}$ value of the soil was more greatly enhanced by mHAP. Gilbert et al. [30] and Cui et al. [18] suggested that nanomaterials can easily aggregate, leading to an alteration to their surface sorption and ability to migrate while decreasing their dissolution rates. mHAP has a larger particle size, as compared to nHAP making it much more difficult for mHAP to aggregate. Therefore, we hypothesized that the higher dissolution rate was the primary reason for the increases in the $\mathrm{pH}$ value and for its increased immobilization effects. Nevertheless, further studies are needed in order to verify this hypothesis.

\section{Conclusions}

The effectiveness of two different sizes of HAP particle, nanometer size particle of HAP (nHAP) and micrometer size particle of HAP (mHAP), was assessed for their ability of reducing the bioavailability of $\mathrm{Pb}, \mathrm{Zn}, \mathrm{Cu}$, and $\mathrm{Cr}$. The results showed that both $\mathrm{mHAP}$ and $\mathrm{nHAP}$ had significant effect on reducing the uptake of $\mathrm{Pb}, \mathrm{Zn}, \mathrm{Cu}$, and $\mathrm{Cr}$ by pakchoi. Furthermore, both mHAP and nHAP were efficient in covering $\mathrm{Pb}, \mathrm{Zn}, \mathrm{Cu}$, and $\mathrm{Cr}$ from nonresidual into residual forms. However, mHAP was superior to nHAP immobilization of $\mathrm{Pb}, \mathrm{Zn}, \mathrm{Cu}$, and $\mathrm{Cr}$ in metal-contaminated soil and reducing the $\mathrm{Pb}, \mathrm{Zn}, \mathrm{Cu}$, and $\mathrm{Cr}$ by pakchoi. In addition, mHAP and nHAP were both more efficient in transferring bioavailable $\mathrm{Pb}$ into less bioavailable form than $\mathrm{Zn}, \mathrm{Cu}$, and $\mathrm{Cr}$. This may be due to the fact that more $\mathrm{Pb}$ was formed into insoluble pyromorphite like minerals after treated with HAP. However, in this study, it was suggested that HAP with micrometer size was more effective immobilization soil metals than nanometer size HAP, possibly due to its higher dissolution rate.

\section{Conflict of Interests}

The authors declare that there is no conflict of interests regarding the publication of this paper.

\section{Acknowledgment}

This work was supported by the National Spark Program of China (no. 2012GA780051). 


\section{References}

[1] I. Mohamed, B. Ahamadou, M. Li et al., "Fractionation of copper and cadmium and their binding with soil organic matter in a contaminated soil amended with organic materials," Journal of Soils and Sediments, vol. 10, no. 6, pp. 973-982, 2010.

[2] N. Karami, R. Clemente, E. Moreno-Jiménez, N. W. Lepp, and L. Beesley, "Efficiency of green waste compost and biochar soil amendments for reducing lead and copper mobility and uptake to ryegrass," Journal of Hazardous Materials, vol. 191, no. 1-3, pp. 41-48, 2011.

[3] H. M. Chen, C. R. Zheng, C. Tu, and Y. G. Zhu, "Heavy metal pollution in soils in China: status and countermeasures," Ambio, vol. 28, no. 2, pp. 130-134, 1999.

[4] X. D. Cao, L. Q. Ma, M. Chen, S. P. Singh, and W. G. Harris, "Phosphate-induced metal immobilization in a contaminated site," Environmental Pollution, vol. 122, no. 1, pp. 19-28, 2003.

[5] X. D. Cao, A. Wahbi, L. Ma, B. Li, and Y. Yang, "Immobilization of $\mathrm{Zn}, \mathrm{Cu}$, and $\mathrm{Pb}$ in contaminated soils using phosphate rock and phosphoric acid," Journal of Hazardous Materials, vol. 164, no. 2-3, pp. 555-564, 2009.

[6] S. B. Chen, M. G. Xu, Y. B. Ma, and J. Yang, "Evaluation of different phosphate amendments on availability of metals in contaminated soil," Ecotoxicology and Environmental Safety, vol. 67, no. 2, pp. 278-285, 2007.

[7] V. Misra and P. K. Chaturvedi, "Plant uptake/bioavailability of heavy metals from the contaminated soil after treatment with humus soil and hydroxyapatite," Environmental Monitoring and Assessment, vol. 133, no. 1-3, pp. 169-176, 2007.

[8] J. Chen, Y. Wang, D. Zhou, Y. Cui, S. Wang, and Y. Chen, "Adsorption and desorption of $\mathrm{Cu}(\mathrm{II}), \mathrm{Zn}(\mathrm{II}), \mathrm{Pb}(\mathrm{II})$, and Cd(II) on the soils amended with nanoscale hydroxyapatite," Environmental Progress and Sustainable Energy, vol. 29, no. 2, pp. 233-241, 2010.

[9] Z. Z. Zhang, M. Y. Li, W. Chen, S. Zhu, N. Liu, and L. Zhu, "Immobilization of lead and cadmium from aqueous solution and contaminated sediment using nano-hydroxyapatite," Environmental Pollution, vol. 158, no. 2, pp. 514-519, 2010.

[10] R. K. Lu, Analytical Methods for Soils and Agricultural Chemistry, China Agricultural Science and Technology Press, Beijing, China, 1999.

[11] G. Rauret, R. Rubio, and J. F. Lopez-sanchez, "Opitimiaztion of tessierprocedure for metal solid speciation in river sediments," Trends in Analytical Chemistry, vol. 36, pp. 69-83, 1989.

[12] X. C. Chen and Y. S. Cui, "Effects of dry and fresh states of Brassica chinensis on the oral bioaccessibility of lead," Asian Journal of Ecotoxicology, vol. 4, no. 6, pp. 793-799, 2009 (Chinese).

[13] P. Li, X. X. Wang, T. L. Zhang, D. Zhou, and Y. He, "Effects of several amendments on rice growth and uptake of copper and cadmium from a contaminated soil," Journal of Environmental Sciences, vol. 20, no. 4, pp. 449-455, 2008.

[14] P. Zhang and J. A. Ryan, "Formation of chloropyromorphite from Galena ( $\mathrm{PbS}$ ) in the presence of hydroxyapatite," Environmental Science and Technology, vol. 33, no. 4, pp. 618-624, 1999.

[15] X. D. Cao, L. Q. Ma, S. P. Singh, and Q. Zhou, "Phosphateinduced lead immobilization from different lead minerals in soils under varying $\mathrm{pH}$ conditions," Environmental Pollution, vol. 152, no. 1, pp. 184-192, 2008.

[16] J. Boisson, A. Ruttens, M. Mench, and J. Vangronsveld, "Evaluation of hydroxyapatite as a metal immobilizing soil additive for the remediation of polluted soils. Part 1. Influence of hydroxyapatite on metal exchangeability in soil, plant growth and plant metal accumulation," Environmental Pollution, vol. 104, no. 2, pp. 225-233, 1999.

[17] H. Eslami, M. Solati-Hashjin, and M. Tahriri, "Effect of fluorine ion addition on structural, thermal, mechanical, solubility and biocompatibility characteristics of hydroxyapatite nanopowders," Advances in Applied Ceramics, vol. 109, no. 4, pp. 200-212, 2010.

[18] H. B. Cui, J. Zhou, and Q. G. Zhao, "Fractions of Cu,Cd and enzyme activities in a contaminated soil as affected by applications of micro- and nanohydroxyapatite," Journal of Soils and Sediments, vol. 13, no. 4, pp. 742-752, 2013.

[19] C. W. Gray, R. G. McLaren, A. H. C. Roberts, and L. M. Condron, "Sorption and desorption of cadmium from some New Zealand soils: effect of $\mathrm{pH}$ and contact time," Australian Journal of Soil Research, vol. 36, no. 2, pp. 199-216, 1998.

[20] L. Q. Ma and G. N. Rao, "Effects of phosphate rock on sequential chemical extraction of lead in contaminated soils," Journal of Environmental Quality, vol. 26, no. 3, pp. 788-794, 1997.

[21] N. T. Basta and R. Gradwohl, "Estimation of Cd, Pb, and Zn bioavailability in smelter-contaminated soils by a sequential extraction procedure," Soil and Sediment Contamination, vol. 9, no. 2, pp. 149-164, 2000.

[22] P. J. C. Favas, J. Pratas, M. E. P. Gomes, and V. Cala, "Selective chemical extraction of heavy metals in tailings and soils contaminated by mining activity: environmental implications," Journal of Geochemical Exploration, vol. 111, no. 3, pp. 160-171, 2011.

[23] D. S. Lin and Q. X. Zhou, "Effects of soil amendments on the extractability and speciation of cadmium, lead, and copper in a contaminated soil," Bulletin of Environmental Contamination and Toxicology, vol. 83, no. 1, pp. 136-140, 2009.

[24] S. B. Chen, Y. G. Zhu, Y. B. Ma, and G. McKay, "Effect of bone char application on $\mathrm{Pb}$ bioavailability in a $\mathrm{Pb}$-contaminated soil," Environmental Pollution, vol. 139, no. 3, pp. 433-439, 2006.

[25] X. D. Cao, L. Q. Ma, D. R. Rhue, and C. S. Appel, "Mechanisms of lead, copper, and zinc retention by phosphate rock," Environmental Pollution, vol. 131, no. 3, pp. 435-444, 2004.

[26] R. Q. Liu and R. Lai, "Nanoenhanced materials for reclamation of mine lands and other degraded soils: a review," Journal of Nanotechnology, vol. 2012, Article ID 461468, 18 pages, 2012.

[27] M. Wang, L. Chen, S. B. Chen, and Y. Ma, "Alleviation of cadmium-induced root growth inhibition in crop seedlings by nanoparticles," Ecotoxicology and Environmental Safety, vol. 79, pp. 48-54, 2012.

[28] R. Liu and D. Zhao, "Reducing leachability and bioaccessibility of lead in soils using a new class of stabilized iron phosphate nanoparticles," Water Research, vol. 41, no. 12, pp. 2491-2502, 2007.

[29] R. Liu, "In-Situ lead remediation in a shoot-range soil using stabilized apatite Nanoparticles," in Proceedings of the 85th ACS Colloid and surface Science Symposium, McGill Univeristy, Montreal, Canada, June 2011.

[30] B. Gilbert, R. K. Ono, K. A. Ching, and C. S. Kim, "The effects of nanoparticle aggregation processes on aggregate structure and metal uptake," Journal of Colloid and Interface Science, vol. 339, no. 2, pp. 285-295, 2009. 

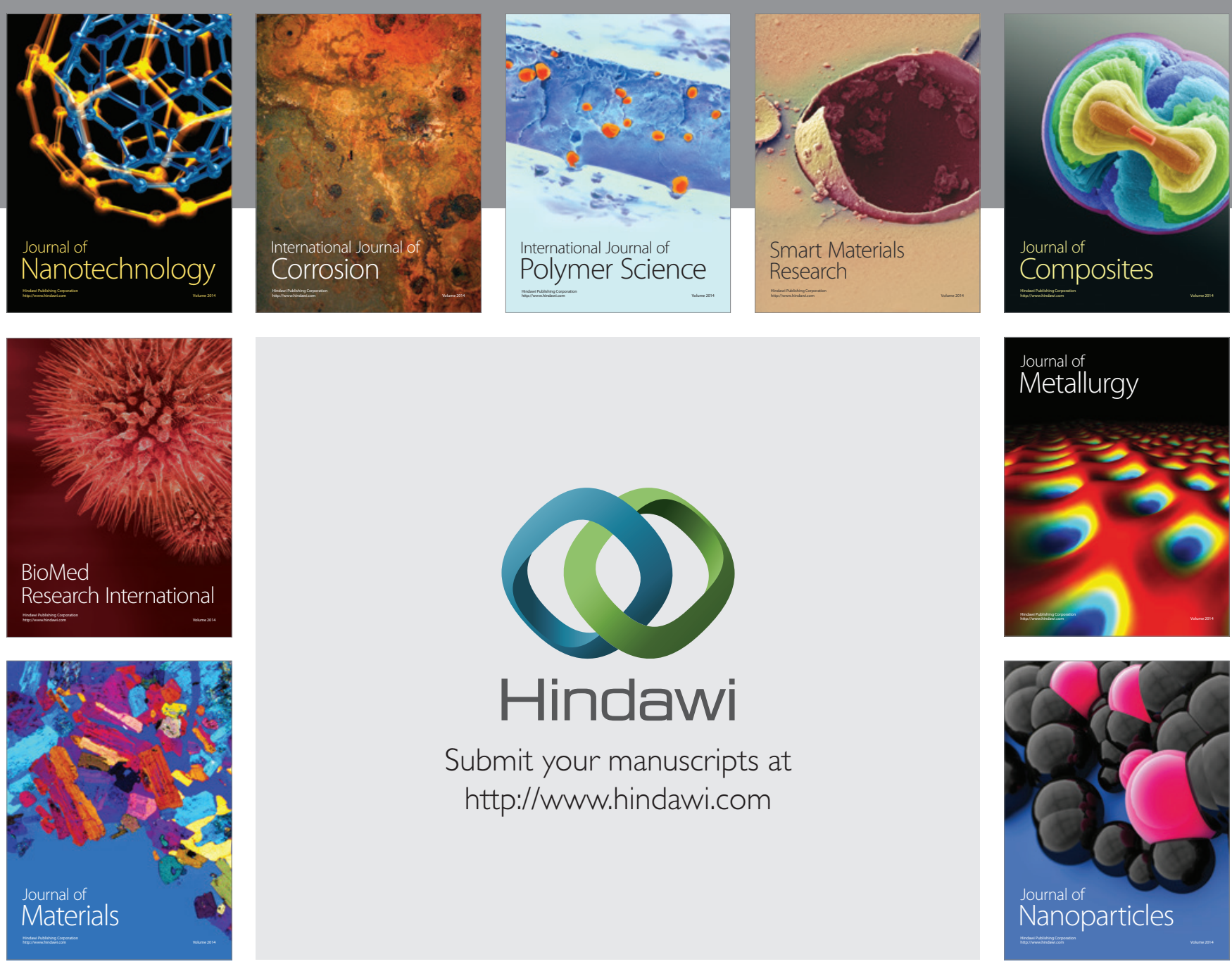

Submit your manuscripts at http://www.hindawi.com
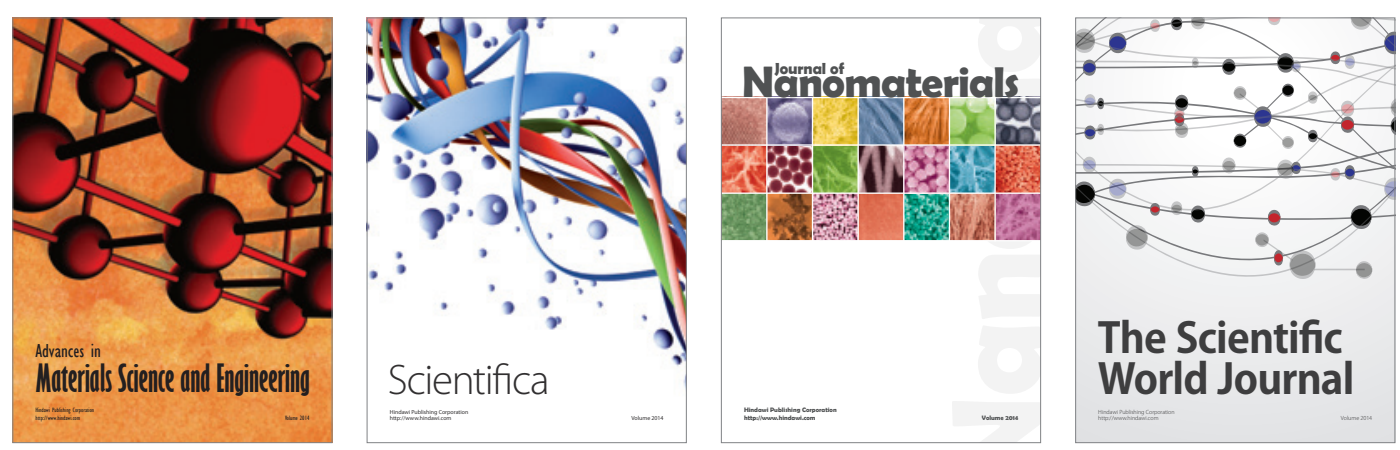

\section{The Scientific World Journal}
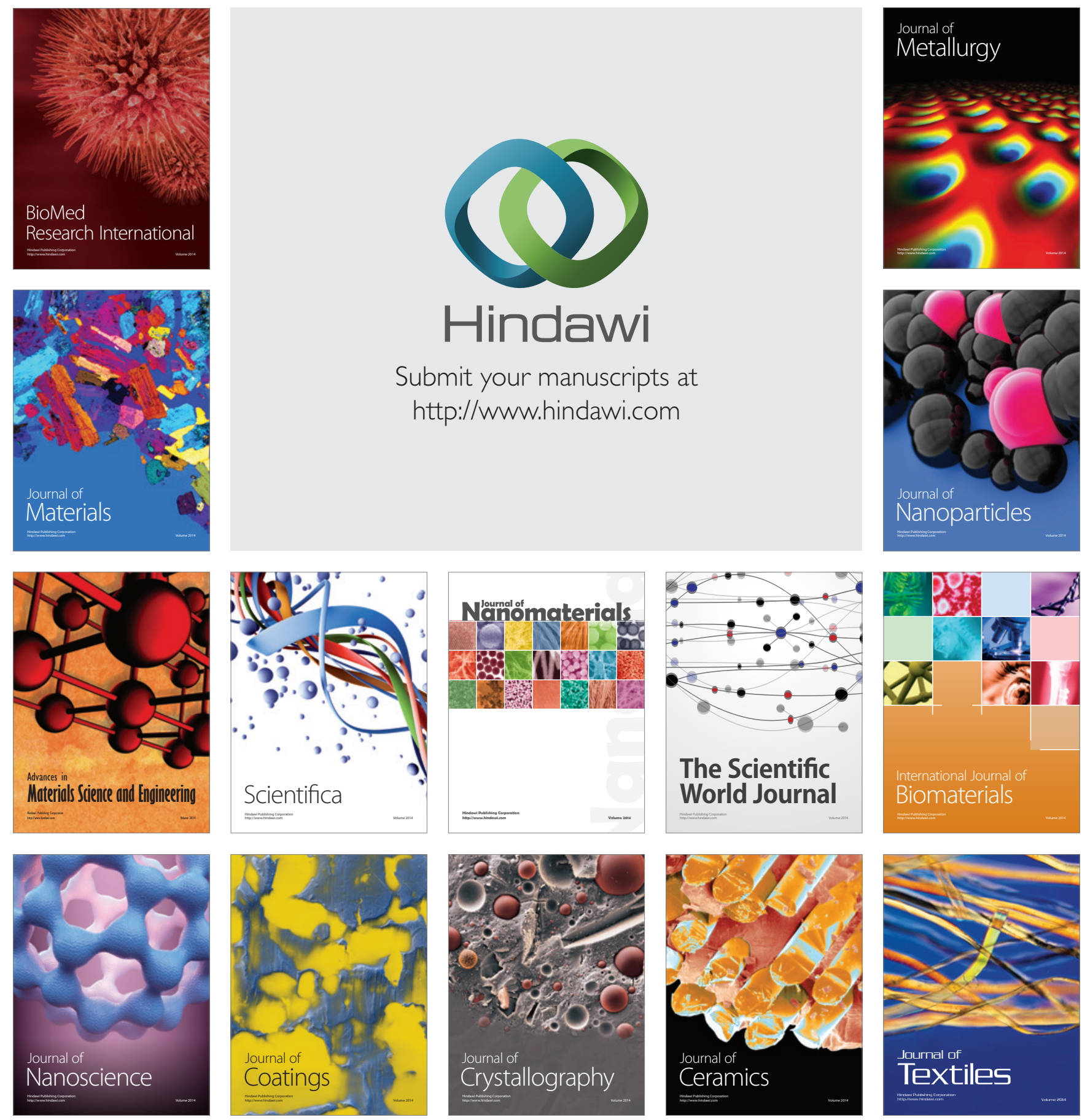